Rev. Bras. Saúde Prod. Anim., Salvador, v.13, n.4, p.938-953 out./dez., 2012 http://www.rbspa.ufba.br ISSN 15199940

\title{
Inovações e desafios na avaliação de alimentos na nutrição de ruminantes ${ }^{1}$
}

\author{
Innovations and challenges in food evaluation in ruminant nutrition
}

\author{
CANESIN, Roberta Carrilho ${ }^{2 *}$; FIORENTINI, Giovani ${ }^{2}$; BERCHIELLI, Telma \\ Teresinha $^{2}$
}

\footnotetext{
${ }^{1}$ Revisão apresentada no Congresso Brasileiro de Zootecnia (ZOOTEC 2011).

${ }^{2}$ Universidade Estadual Paulista, Faculdade de Ciências Agrária e Veterinárias, Departamento de Zootecnia, Jaboticabal, São Paulo, Brasil.

*Endereço para correspondência: betacanesin@ @otmail.com
}

\section{RESUMO}

A avaliação de alimentos é um dos principais pontos a serem observados no setor de nutrição animal, a qual diz respeito à utilização de métodos para descrever alimentos ao seu público e à sua capacidade de sustentar diferentes tipos e níveis de desempenho animal. Atualmente, as pesquisas têm buscado relacionar o conteúdo de nutrientes dos alimentos com seu aproveitamento digestivo e metabólico. A nutrição animal é uma ciência bastante dinâmica, sempre lança mão de novas tecnologias e estratégias para melhorar o aproveitamento dos alimentos e busca novas metodologias para respondem às demandas emergenciais.. Dessa forma, o estabelecimento de estratégias apropriadas para obtenção de respostas é essencial para que o sucesso na pesquisa seja atingido. Assim, esta revisão irá abordar e discutir as principais técnicas utilizadas na avaliação de alimentos aplicadas à nutrição de ruminantes.

Palavras - chave: análise química, digestibilidade, FDNi, n-alcanos, produção de gás.

\section{SUMMARY}

The food evaluation is one of the main points to be observed in the animal nutrition sector, which concerns the use of methods to describe animal feed as well its ability to support different types and levels of animal performance. Currently, researches have tried finding relationship between the nutrient content of foods and their digestive and metabolic exploitation. The animal nutrition is a science rather dynamic, always making use of new technologies and strategies to improve the utilization of food, always searching new methods as new answers to questions are necessary. Thus, the establishment of appropriate methodologies to obtaining the answers is essential to achieve success in search. This way this review will address and discuss some of the main techniques used in feed evaluation applied to ruminant nutrition

Keywords: chemical analysis, digestibility, gas production, iNDF, n-alkanes.

\section{INTRODUÇÃO}

Durante a evolução, os animais ruminantes desenvolveram características anatômicas e simbióticas, que lhes permitem utilizar eficientemente carboidratos estruturais como fonte de energia e compostos nitrogenados não proteicos como fonte de proteína (VALADARES FILHO \& PINA, 2006). Além desse potencial, os ruminantes possuem uma importante função como produtores de bens, em geral, para a humanidade.

A avaliação de alimentos é um dos principais pontos a serem observados no setor de nutrição animal, a qual diz respeito à utilização de métodos para descrever alimentos ao seu público e à sua capacidade de sustentar diferentes tipos e níveis de desempenho animal. A 
maior ênfase é dada à determinação da composição química específica, embora as características físicas dos alimentos também sejam importantes. O objetivo prático de avaliação de alimentos é otimizar a eficiência de utilização de alimentos para animais, produção animal e, finalmente, o retorno financeiro ao produtor. Nesse contexto, é importante para estabelecer o potencial dos alimentos e a necessidade de suplementos apropriados, a fim de superar as deficiências nutricionais e elevar o nível de desempenho.

A pesquisa em nutrição animal exerce, dentro da área de produção animal, imprescindível papel, visto fazer uso de metodologias que possibilitem fornecer informações a respeito dos ingredientes utilizados na alimentação animal e prever a maneira como a estrutura dos alimentos irá afetar o seu desempenho. Atualmente, as pesquisas têm buscado relacionar o conteúdo de nutrientes dos alimentos com seu aproveitamento digestivo e metabólico. Dessa forma, o estabelecimento de metodologias apropriadas para obtenção de respostas é essencial para que o sucesso na pesquisa seja atingido (BERCHIELLI et al., 2011). Diante do exposto, nesta revisão serão apresentadas e discutidas as principais técnicas de avaliação de alimentos aplicadas à nutrição de ruminantes.

\section{MÉTODOS PARA AVALIAÇÃO DA COMPOSIÇÃO BROMATOLÓGICA DOS ALIMENTOS}

O denominado método de Weende é um dos mais utilizados na nutrição animal,, desenvolvido, em 1864, por cientistas alemães, que envolve a determinação da matéria seca, matéria mineral ou cinzas, proteína bruta, extrato etéreo, fibra bruta e extrato não nitrogenado. A matéria seca (MS) representa a perda da umidade do alimento, geralmente, realizada por secagem em estufa com circulação de ar forçada a $60^{\circ} \mathrm{C}$ (pressecagem) e $100^{\circ} \mathrm{C}$ (secagem definitiva), determinada, gravimetricamente, pelo resíduo remanescente após a secagem. A matéria mineral ou cinzas é determinado pelo aquecimento da amostra à $600^{\circ} \mathrm{C}$, até a combustão total da matéria orgânica, e o resíduo ou cinzas pode ser usado para determinar o teor de elementos minerais individuais no alimento (SILVA \& QUEIROZ, 2002).

O teor de proteína bruta é calculado a partir do teor de nitrogênio $(\mathrm{N})$ e obtido pelo método Kjeldahl. Ocorre que, nos dias atuais, está em voga o método de Dumas, cuja dinâmica envolve a combustão da amostra, e a determinação é realizada através do $\mathrm{N}$ gasoso liberado. O conteúdo proteico é determinado através da multiplicação do teor de $\mathrm{N}$ pelo fator de conversão de cada alimento, ou através do fator universal 6,25 (assumindo que o $\mathrm{N}$ derivado de proteína contém $16 \% \mathrm{~N}$ ).

$\mathrm{Na}$ comparação dos métodos de Kjeldahl e Dumas, Sader et al. (2004) verificaram que o desvio padrão do teor de $\mathrm{N}$ dentro e entre estes estão de acorco com os intervalos permitidos pela literatura. Se esse dado for associado ao fato da metodologia de Dumas consistir em uma técnica não poluente ao ambiente, esta metodologia pode ser considerada capaz de substituir com vantagens $\mathrm{o}$ procedimento de Kjeldahl, em análises de rotina em laboratórios de nutrição animal.

Nas análises e caracterização das gorduras, os lipídios são especificados de uma maneira geral como extrato etéreo (EE). No entanto, quando adicionado a estes, o éter extrai pigmentos vegetais como clorofila, 
xantofila e caroteno, além de traços de diversas outras substâncias. Remove ainda certos óleos essenciais que não são produtos lipídicos e que consistem basicamente de ésteres, aldeídos e éteres. Assim, o teor de EE pode ser superestimado em alimentos ricos em ceras e pigmentos (clorofila, xantofila e outros sem valor energético) devido à solubilidade destes compostos em éter.

Fibra bruta (FB) é uma fração dos alimentos composta por carboidratos estruturais resistentes ao tratamento sucessivo com ácido e base diluídos. Uma amostra seca e desengordurada é submetida à digestão com uma solução ácida e depois com uma solução básica fraca. Essa metodologia subestima os reais valores de fibra, pois o tratamento com álcali solubiliza porções de lignina e hemicelulose. Por sua vez, a lignina solubilizada torna-se parte do extrato não nitrogenado (ENN), o que resulta, muita vezes, na digestibilidade da FB ser maior que a do ENN.

$\mathrm{O}$ extrativo não nitrogenado (ENN) corresponde, teoricamente, aos carboidratos não estruturais, possui erros acumulativos das demais determinações, uma vez ser obtido por meio do cálculo de outras análises (por meio de informações das demais análises $(\mathrm{ENN}=$ $100-(\mathrm{PB}+\mathrm{EE}+\mathrm{FB}+\mathrm{MM}))$. $\mathrm{O}$ maior desses erros é decorrente da subestimação dos valores de FB por solubilização de parte da celulose e da lignina em álcali, a superestimar os ENN.

O método de Van Soest, desenvolvido em 1967, na Cornell University, permite identificar os constituintes vegetais, em conteúdo e parede celulares, através da extração da biomassa da planta, com detergente neutro, para deixar um resíduo fibroso, predominantemente, hemicelulose, celulose e lignina ou com detergente ácido para deixar resíduos de celulose e lignina. Esse método também é utilizado no fracionamento do nitrogênio, com a determinação do nitrogênio insolúvel em detergente neutro (NIDN) e nitrogênio insolúvel em detergente ácido (NIDA), adotado em sistemas atuais de exigências nutricionais. Segundo Berchielli et al. (2011) certos fatores podem ser considerados como fontes de variação na determinação de FDN e FDA, como a contaminação da FDN por amido, para a qual se recomenda o uso de amilase estável à alta temperatura; a contaminação da FDA com pectina, sugere-se a análise sequencial, análise seguida de FDN e FDA em uma mesma amostra; e a contaminação com minerais, propõemse que os resultados de FDN e FDA sejam expressos como livres de cinzas, pela ação da queima das amostras em mufla, a $600^{\circ} \mathrm{C}$. No entanto, determinadas modificações realizadas na metodologia para obtenção dos valores de FDN, não são adotadas, de modo a resultar em ausência de padronização e pouca confiabilidade na comparação de resultados.

Com o objetivo de diminuir o tempo de análises laboratoriais, Dechamps (1999) utilizou a autoclave (40 minutos a temperatura $120^{\circ} \mathrm{C}$ ) nas análises de FDN. Essa inovação permitiu executar até 120 amostras por operação, o que aumentou a produtividade no laboratório, com sensível economia de reagentes. Atualmente, Senger et al. (2008) testaram diferentes tempos e temperaturas de autoclave para análises de FDN e FDA a fim de encontrar um procedimento alternativo ao convencional e concluíram que as análises de forragem ou concentrado podem ser realizadas simultaneamente, em autoclave, por meio de sacos de filtro e uma temperatura de $110^{\circ} \mathrm{C}$, durante 40 minutos.

A determinação do teor de lignina é feita a partir da FDA. Duas metodologias podem ser utilizadas para esse fim: numa delas a determinação é realizada por meio 
de solução de ácido sulfúrico a 72\% (LAD ou lignina "Klason") ou por meio do permanganato de potássio (Lignina permanganato), conforme descrito por Silva \& Queiroz, (2002). Na determinação pelo método do ácido sulfúrico, ocorre a solubilização da celulose e o resíduo consiste de lignina e cinzas insolúveis em detergente ácido. Pelo método do permanganato de potássio, a lignina é oxidada por meio de solução tamponada de ácido acético e permanganato de potássio, que contém ferro trivalente e prata monovalente, como catalisadores. Os óxidos de ferro e de manganês depositados são dissolvidos numa solução alcoólica, com ácido oxálico e ácido clorídrico, de forma a remanescer no cadinho apenas celulose e minerais insolúveis. Deve-se ressaltar que a escolha do método depende do tipo de material a ser analisado e da finalidade da pesquisa a ser realizada.

A espectroscopia de reflectância do infravermelho proximal (NIRS) também tem sido adotada para determinação da composição dos alimentos. Em termos de exatidão, precisão, velocidade e custo por unidade de análise, a técnica NIRS, desde que seja calibrada corretamente, é preferível à métodos laboratoriais tradicionais. Entretanto, a técnica, em última análise, consiste em um conjunto de análises padrões de amostras, cuja composição foi determinada por métodos tradicionais (análises químicas). No estudo da técnica NIRS, Fontaneli et al. (2004) observaram que o método NIRS apresentou elevada acurácia na determinação dos teores de PB, FDA e FDN em cultivares de Cynodon sp. e, ainda, mostrou índices de calibração satisfatórios para determinação de minerais.

Atualmente, Decruyenaere et al. (2009) avaliaram a utilização do NIRS para determinação da ingestão e digestibilidade da matéria orgânica com base na análise de fezes ou forragens e confrontaram os resultados àqueles obtidos por técnicas in vivo. Nesse sentido, os autores citam que a acurácia do modelo utilizado pelo NIRS é semelhante, ou melhor, a outros métodos de estimativa, porém Decruyenaere et al. (2009) destacam que o banco de dados utilizado na calibração deve ser bastante amplo para garantir a confiabilidade nos resultados.

\section{ESTIMATIVA DE CONSUMO E EMPREGO DE MARCADORES}

O consumo é o componente que exerce papel de maior importância na nutrição animal, pois determina o nível de nutrientes ingerido e, consequentemente, o seu desempenho (BERCHIELLI et al., 2011). A estimativa acurada do consumo de matéria seca por animais criados em pastejo sempre foi um desafio para os pesquisadores, se considerado o grande número de variáveis, atuantes no controle do consumo, e as limitações impostas pelas metodologias utilizadas para obtenção dessas estimativas. Segundo Valadares Filho et al. (2006), a técnica dos indicadores talvez seja a de maior recorrência e aceitabilidade para a estimação do consumo em bovinos.

Entre os indicadores externos disponíveis, o óxido crômico $\left(\mathrm{Cr}_{2} \mathrm{O}_{3}\right)$ tem sido o mais utilizado, principalmente para cálculo da produção fecal, devido a sua facilidade de incorporação às dietas, ao custo relativamente baixo e simplicidade de análise. Entretanto, Titgemeyer et al. (2001) ressaltaram que o cromo não é aprovado pelo Food and Drug Admiministration (FDA) como aditivo alimentar. 
Nesse contexto, o dióxido de titânio $\left(\mathrm{TiO}_{2}\right)$ surge como alternativa ao cromo na função de indicador em estudos de digestão, visto poder ser adicionado legalmente ao alimento em quantidades que não excedam $1,0 \%$ do produto final. Dessa forma, Titgemeyer et al. (2001) compararam as recuperações fecais em novilhos, por meio do $\mathrm{TiO}_{2}$ ou do $\mathrm{Cr}_{2} \mathrm{O}_{3}$, misturados aos concentrados à base de milho, em diferentes períodos de coleta, e verificaram que as recuperações fecais do $\mathrm{TiO}_{2}$ e do $\mathrm{Cr}_{2} \mathrm{O}_{3}$ foram baixas, durante $\mathrm{o}$ primeiro período de coleta de fezes ( 2 a 6 dias após a aplicação do indicador) e não diferiram entre si nos outros três períodos de coletas, que foram de 7 a 11; 12 a 16; e 17 a 21 dias após o início da aplicação dos indicadores.

Com o mesmo intuito de desenvolver um indicador externo eficaz, a Universidade Federal de Minas Gerais desenvolveu a LIPE® (lignina de madeira moída extraída do Eucaliptus grandis) que é um hidroxifenil propano modificado e enriquecido, isto é, um indicador de digestibilidade e consumo (SALIBA, 2005). A degradação da lignina é um processo oxigêniodependente que impossibilita a sua ocorrência no rúmen, o que a torna capaz de ser usada com sucesso como indicador. A LIPE® foi inicialmente aplicada em estudo de consumo e digestibilidade comparada à coleta total em coelhos, suínos, ovinos, e equinos com diferentes dietas (SALIBA et al., 2003a; SALIBA et al., 2003b). Oliveira et al. (2005) compararam a estimativa de excreção fecal e consumo de matéria seca obtidos pela LIPE® e pelo $\mathrm{Cr}_{2} \mathrm{O}_{3}$, de bovinos da raça Nelore em pastejo de Brachiaria brizantha cv. Marandu. Os autores avaliaram também a estimativa obtida a partir do terceiro dia de infusão do indicador e a partir do sétimo dia. Não foi observada diferença entre os dois indicadores para ambos parâmetros avaliados, tampouco houve influência do período de infusão sobre a excreção dos indicadores.

Outro indicador que tem sido utilizado na estimativa do consumo e digestibilidade são os n-alcanos. Os n-alcanos são hidrocarbonetos alifáticos saturados, cuja fórmula geral é $\mathrm{C}_{\mathrm{n}} \mathrm{H}_{2 \mathrm{n}+2}$, e que representam entre $3 \%$ e $20 \%$ do total dos compostos das ceras insaponificáveis da cutícula em diversas gramíneas estudadas. O uso da técnica dos alcanos para estimar ingestão e digestibilidade, com a associação ou não de outras substâncias, tem se consolidado como uma metodologia consistente e de potencial para auxiliar no entendimento das relações entre os herbívoros e o ambiente pastoril (CAVALHO et al., 2007). Esse método exige cuidados semelhantes aos necessários em qualquer outra técnica baseada em indicadores, isso inclui a obtenção de uma amostra representativa da forragem consumida e das fezes, cuidadosa administração do indicador externo e padrão diurno de excreção fecal (OLIVÁN et al., 2007). Além disso, tem se observado que as características da dieta, em termos de valor nutritivo ou números de componentes, podem influenciar a recuperação fecal dos alcanos sintéticos ou naturais (FERREIRA et al., 2005).

Essa técnica tem sido validada em experimentos realizados em gaiolas de metabolismo, tanto em ovinos (DOVE et al., 2002; LEWIS et al., 2003; VALIENTE et al., 2003; FUKOMOTO et al., 2006; KELI et al. 2008), como em bovinos (HENDRICKSEN et al., 2002; MOLINA et al., 2004; OLIVÁN et al., 2007) e em caprinos (DOVE \& MAYES, 1991; FERREIRA et al., 2005). Recentemente, Morais et al. (2011) validou o método n-alcanos para estimar o consumo e digestibilidade de 
bovinos Nelore, alimentados com gramíneas tropicais (Brachiaria brizantha cv. Marandu). Os autores relataram que a correção das concentrações da recuperação fecal dos n-alcanos, por meio de valores individuais para cada alcano, parece melhorar estimativas de consumo de matéria seca e digestibilidade. Os autores também destacaram a importância de uma correção exata de as concentrações de alcanos nas fezes, a fim de serem obtidos resultados precisos de estimativas de consumo de matéria seca.

Também é possível se estimar o consumo individual do suplemento com uso dos alcanos, quando a composição de alcanos do suplemento é suficientemente diferente da composição do pasto, e a taxa de recuperação do alcano é conhecida (DOVE \& MAYES, 1996). Com tal finalidade, pesquisas que utilizam cera de abelhas têm sido desenvolvidas (DOVE et al., 2002; ELWERT \& DOVE, 2005), cujo conteúdo abriga uma composição distinta de alcanos, para "marcar" o suplemento e, assim, se proceder com estimativas mais acuradas de consumo de suplemento de animais em pastejo.

De acordo com dados observados na literatura, a realização de trabalhos de estimativa de consumo de forragem, através do método dos n-alcanos, parece uma ferramenta bastante promissora. Todavia, o custo é alto. A LIPE tem apresentado bons resultados na determinação do consumo e digestibilidade e pode ser uma opção legítima de indicador para uso em pesquisas na área de nutrição animal.

\section{METODOLOGIAS EMPREGADAS NA AVALIAÇÃO DA DIGESTIBILIDADE}

O objetivo de experimentos de digestibilidade é obter de forma acurada a quantidade de alimento fornecido e a quantidade excretada em determinado período de tempo. Para isso, leva-se em consideração a avaliação do consumo e da produção fecal que pode ser feita através de dois métodos: o convencional, com animais diretamente em gaiolas de metabolismo para coleta total de fezes; ou pela estimativa da produção fecal, com o uso de indicadores.

A partir disso, podem ser determinadas a digestibilidade aparente, na qual fração endógena ou perdas por secreções não são consideradas, e a digestibilidade real ou verdadeira é evidenciada nas descamações do sistema digestório (LANA, 2007). O nitrogênio metabólico fecal varia entre espécies de acordo com o tipo de alimentação consumida. A digestibilidade real é maior ou igual à digestibilidade aparente, com exceção da celulose, na qual este modelo de digestibilidade é igual àquela, pois não existe perda endógena de celulose.

O período do ensaio em experimentos, em delineamento inteiramente casualizado ou de blocos ao acaso, deve ser de aproximadamente 20 dias para ruminantes, com 15 dias de adaptação à gaiola metabólica e à dieta, no intuito de provocar mudanças na população microbiana ruminal. Enquanto a determinação do consumo voluntário através da coleta de alimentos, sobras e fezes deve ser de pelo menos 5 dias. Em contrapartida, Ferreira et al. (2009) avaliaram o período de coleta total de fezes, para estimativa da digestibilidade da matéria seca, cuja variação foi de 3 a 5 dias para bovinos de corte e leite, e não observaram diferenças significativas. Isso os levou a recomendar 3 dias de coleta total.

O cálculo da digestibilidade da matéria seca (DMS) é dado pela fórmula:

DMS $(\%)=[($ MSingerida - MSexcretada nas fezes)/MSingerida] $\mathrm{x} 100$, onde $\mathrm{MS}=$ matéria seca. 
No cálculo da digestibilidade de um ingrediente participante de uma dieta composta, considera-se que não ocorre efeito associativo entre os ingredientes. É fundamental conhecer antecipadamente a digestibilidade dos demais componentes da dieta, para se proceder com o cálculo pelo método da diferença. Nesse caso, a digestibilidade do alimento é dada pela fórmula:

DMS $=[$ MSingerida teste (MSexcretada x MSexcretada do alimento conhecido)]/MSingerida do alimento teste.

Apesar de ser considerado como metodologia mais confiável, apresenta o inconveniente de exigir maior número de animais, controle rigoroso da quantidade ingerida e excretada e instalações adequadas. Normalmente, o custo da implantação das instalações ou aquisição de gaiolas metabólicas é muito alto, o que inviabiliza o uso da metodologia (BERCHIELLI et al., 2011).

A quantificação da síntese de proteína microbiana é mais que necessária, devido à grande importância que os microorganismos bacterianos exercem na digestão e degradação da fibra, além de conferir ao animal proteína microbiana de alto valor nutricional. A estimativa de síntese microbiana ruminal pode ser obtida através de marcadores internos bacterianos como, por exemplo, ácidos nucléicos, purinas totais ou ácido diaminopimélico (DAPA). Para isso, se utilizam animais canulados pósruminalmente e o fluxo duodenal de proteína microbiana é determinado. Porém, essas técnicas são trabalhosas e podem comprometer o bem-estar animal, portanto, seria mais adequado o desenvolvimento de métodos não invasivos para tais fins.

$\mathrm{O}$ uso dos derivados de purinas como indicador para estimar a síntese microbiana no rúmen foi, primeiramente, proposto por Blaxter e Martin em 1962, citados por Fujihara et al. (1987), e demonstrou relação direta entre a excreção urinária de metabólitos de purinas e a produção de nitrogênio microbiano em ovelhas. No entanto, maiores progressos no estabelecimento dessa técnica têm sido obtidos em bovinos e ovinos (CHEN et al., 1995). Para o uso da técnica de derivados de purinas, assume-se que o fluxo intestinal dos ácidos nucléicos é predominantemente de origem microbiana e que, após a digestão intestinal, as bases purinas (adenina e guanina) são absorvidas, catabolizadas e excretadas, proporcionalmente, na urina. Os derivados de purinas são excretados como hipoxantina, xantina, ácido úrico e alantoína (YU et al., 2002).

Em bovinos, alantoína e ácido úrico são os principais derivados de purinas presentes na urina, em razão da alta atividade no sangue e nos tecidos da enzima xantina oxidase, que converte xantina e hipoxantina em ácido úrico antes da excreção. Caprinos, ovinos e suínos, no entanto, excretam quantidades substanciais de xantina e hipoxantina, em virtude da menor atividade da enzima xantina oxidase no plasma (BELENGUER et al., 2002).

$\mathrm{O}$ uso da técnica de derivados de purina na urina requer a coleta total de urina, mas resultados promissores têm sido obtidos com coleta de amostras spot de urina (CHEN et al., 1995), o que pode simplificar a estimativa da produção de urina em condições de campo. A creatina é uma substância sintetizada nos músculos e seu metabólito (a creatinina) pode ser excretado pela urina, em função relativamente constante ao peso vivo (RENNÓ et al., 2000). Por isso, a excreção urinária de creatinina tem sido usada para obter-se a estimativa da produção diária de 
urina, de derivados de purinas e de proteína bacteriana a partir de amostras spot.

No estudo da estimativa de produção de urina, com base na excreção de creatinina em amostras pontuais, Kozloski et al. (2005) previram que esta só será confiável, se, pelo menos, num dos animais representativos do experimento, for realizada coleta total de urina, de modo a ter a excreção média de creatinina por unidade de peso corporal. Os autores sugeriram ainda que as amostras spot devam ser coletadas em diferentes horários, ao longo do dia, para ter assim uma amostra composta e representativa, num ciclo de 24 horas. Uma das limitações seria em relação ao cálculo, pois assume-se que praticamente não há contribuição de purinas totais dos alimentos disponível para absorção intestinal, e utiliza uma relação constante entre purinas totais e nitrogênio total nas bactérias. Aliado a isso, está o fato das equações utilizadas serem específicas para cada espécie animal (ex: bovinos ou ovinos).

A estimativa de síntese microbiana por derivados de purinas tem demonstrado alta correlação com as medidas de fluxo de bases purinas no duodeno (GONZÁLES RONQUILLO et al., 2004). Os autores também recomendaram o uso de derivados de purinas para estimar a produção de proteína microbiana, porém, observaram que método dos ácidos nucléicos, normalmente, possui coeficientes de determinação mais elevados e coeficientes de variação mais baixos, em relação aos derivados de purinas.

A técnica in situ propicia uma estimativa rápida e simples da degradação dos nutrientes no rúmen, além de permitir o acompanhamento de degradação ao longo do tempo (MEHREZ \& ORSKOV, 1977). Baseia- se no desaparecimento da amostra de alimento acondicionada em sacos de náilon ou outro material sintético, incubados no rúmen por diferentes períodos de tempo. As principais vantagens dessa técnica estão relacionadas à sua rápida e fácil execução, à necessidade de pequena quantidade de alimentos e ao fato de permitir $o$ contato íntimo entre $o$ alimento testado e o ambiente ruminal.

Segundo Vanzant et al. (1998) técnicas in situ têm sido utilizadas intensivamente por mais de duas décadas, primeiramente, para comparar características de degradação entre os alimentos e melhorar o conhecimento da digestão ruminal. Recentemente, as dietas são bem balanceadas e exigem conhecimento das características de degradação ruminal dos alimentos a fim de melhorar a performance animal.

Apesar da difusão, a técnica ainda apresenta problemas de padronização quanto ao seu uso, devido ao grande número de variáveis envolvidas, como porosidade do náilon, tamanho da partícula do alimento, tempo de incubação e dieta dos animais. Torna-se de fundamental importância o conhecimento dos principais fatores que a influenciam e seus mecanismos de controle. Dessa forma, reunir o maior número de informações possível, a fim de estabelecer um padrão de trabalho para que os valores obtidos sejam corretos e passíveis de aplicação (CAMPOS et al., 2004).

$\mathrm{Na}$ preparação do saco de náilon recomenda-se a utilização de tecido com $100 \%$ de poliamida, resistente a temperaturas elevadas; não resinado; com porosidade na faixa de 40 a 60 micra (NOCEK, 1988), não inferior a 30 micra e não superior a 100 micra; que permita a entrada dos microrganismos no interior dos sacos para degradação do alimento, remoção dos produtos finais 
da degradação e redução das perdas de amostras não degradadas (VAN HELLEN \& ELLIS, 1977). A quantidade ideal de amostra incubada deve fornecer resíduo suficiente para que, após a degradação, seja possível a execução das análises químicas desejadas. Um limite na relação entre quantidade de amostra e área superficial de 10$20 \mathrm{mg} / \mathrm{cm}^{2}$ deveria ser utilizado para a maior parte das forragens $\mathrm{e}$ concentrados.

Diante da perspectiva de utilização de vários tecidos, para realização de procedimentos in situ de estimação das concentrações de resíduos indigestíveis, gera-se demanda premente para avaliação desses materiais quanto a aspectos primários de interferência na exatidão e precisão dos resultados, e a secundários, que envolvem custos $\mathrm{e}$ praticidade operacional. Casali et al. (2009) analisaram a integridade física pós-incubação e pós-extração com detergente e avaliaram as perdas de partículas e as estimativas dos teores de FDNi de alguns alimentos para ruminantes obtidas em procedimento in situ, por meio de sacos confeccionados com os tecidos náilon $(50 \mu \mathrm{m})$, F57 (Ankom®) e tecido não tecido (TNT $\left.100 \mathrm{~g} / \mathrm{m}^{2}\right)$. Em suma, os autores verificaram que a utilização do tecido F57 (Ankom®) é recomendada para obtenção dos teores de fibra em detergente neutro indigestível pela técnica in situ em função da exatidão das estimativas obtidas. O tecido não tecido $\left(100 \mathrm{~g} / \mathrm{m}^{2}\right)$ pode constituir alternativa de menor custo ao F57, em estudos para quantificação de compostos fibrosos indigestíveis em alimentos, uma vez que apresentam, em geral, estimativas com níveis similares de exatidão e precisão. Contudo, em virtude de pequenas divergências observadas no estudo, os autores sugeriram novas avaliações do tecido não tecido para que sua recomendação possa ser realizada de forma generalizada. Casali et al (2009) ainda apontam que a utilização do náilon em procedimentos similares, embora resulte em maior precisão, conduz a estimativas não exatas, em decorrência da perda significativa de partículas fibrosas insolúveis.

A determinação do número de horários de incubação dependerá do tipo de alimento a ser avaliado. De acordo com Ørskov et al. (1988), para a maioria dos suplementos proteicos, os tempos 2; 6; $12 ; 24$ e 36 horas proporcionam informações adequadas para a descrição da curva. No caso dos fenos, palhas e outros materiais fibrosos, geralmente, os tempos de incubação são mais prolongados e chegam a totalizar até 144 horas. De modo a visar à padronização nos protocolos, para estimação dos teores de compostos indigestíveis em procedimentos in situ, Casali et al. (2008) avaliaram a influência do tempo de incubação e do tamanho de partículas sobre as estimativas dos compostos indigestíveis (MSi, FDNi e FDAi) em alimentos e fezes de bovinos. Os autores sugeriram a utilização de partículas de $2 \mathrm{~mm}$, em protocolos in situ, por possiblitar maior precisão das estimativas e ressaltaram que a utilização de sacos confeccionados com TNT, em protocolos de estimação in situ, dos teores de MSi e FDNi, devem ser utilizados tempos de incubação de 240 horas para obtenção de estimativas mais exatas das frações indigestíveis. Para avaliação da fração FDAi, sugeriram tempos de 264 horas.

Os métodos in vitro são mais simples e econômicos para se obter a digestibilidade dos alimentos e visam a reproduzir as condições favoráveis à fermentação do rúmen-retículo, com o uso de líquido ruminal ou enzimas digestivas. A técnica apresenta aplicações 
e vantagens, tais como: a determinação da taxa de digestão e da extensão de digestão, relacionada à digestibilidade da forragem, que afeta a taxa de passagem e o consumo; e a estimativa do consumo de forragem, que pode ser obtida pela produção fecal dividida pela indigestibilidade do alimento (LANA, 2007).

Baseada nas vantagens apresentadas, foi desenvolvida uma técnica in vitro que avalia a digestibilidade do alimento quanto à produção cumulativa de gases. A técnica de produção de gás (MENKE et al.,1979; PELL \& SCHOFIELD, 1993; THEODOROU et al., 1994) consiste, basicamente, em medir a produção total de gás liberado pela fermentação de uma amostra incubada, em líquido ruminal tamponado. As vantagens dessa técnica sobre as outras in vitro, como a de Tilley \& Terry (1963), para a avaliação de alimentos, foram destacadas por Blümmel \& Ørskov (1993) e Makkar et al. (1995). Outros métodos in vitro são baseados em mensurações gravimétricas que seguem o desaparecimento do substrato (componentes que podem ou não contribuir para a fermentação), enquanto a mensuração de gás concentra-se no surgimento de produtos de fermentação (substâncias solúveis, mas não fermentáveis, sem contribuir para a produção de gás). Essa diferença no princípio do método faz com que essa técnica apresente alta correlação com a digestibilidade in vivo. Além disso, o método de produção de gás possui a vantagem de determinar a cinética de fermentação em uma única amostra, o que torna necessária uma quantidade relativamente pequena. Isso permite que um maior número de amostras seja avaliado, ao mesmo tempo, e a capacidade de exercer controle experimental. E como desvantagem o baixo peso da amostra incubada, o que dificulta a homogeneidade do material (SANTOS et al., 2003).

As questões metodológicas relacionadas com a técnica de produção de gás in vitro incluem os diferentes equipamentos utilizados (por exemplo, seringas versus transdutores de pressão) e os efeitos da origem e preparação do inóculo, composição e preparação do meio, bem como a preparação do substrato.

Em 2005, a revista Animal Feed Science and Technology reconheceu o papel crescente da técnica de produção de gás in vitro, e, por essa razão, publicou artigos relacionados com metodologias, implicações e aplicações, e efeitos de diversos fatores que podem influenciar o desenvolvimento dessa técnica. Rymer et al.(2005) concluíram que o inóculo é obviamente uma fonte crucial de variação, embora, quando fluido de rúmen é usado, o principal é assegurar que a atividade microbiana seja suficientemente alta para não afetar a taxa e a extensão da fermentação, sobre a qual a variabilidade oriunda do inoculo é relativamente pequena.

Outro ponto em destaque foi a produção de metano dos animais, por meio da técnica in vitro. Getachew et al. (2005) relataram que as estimativas da quantidade de metano $\left(\mathrm{CH}_{4}\right)$ produzida a partir do simples procedimento in vitro foram semelhantes aos previamente determinados in vivo. Isso sugere que esta pode ser usada para estimar a produção de metano in vivo e, assim, avaliar a medida em que produção de metano pode ser alterada, quer por mudanças nos ingredientes da dieta e/ou incluindo aditivos para modificar o ambiente ruminal, por exemplo, para deprimir o crescimento de bactérias metanogênicas no rúmen.

Os recipientes de fermentação in vitro formados por componentes idênticos como todos os outros, com exclusão de 
qualquer substrato, são chamados de "branco" e são rotineiramente utilizados durante as incubações de produção de gás, para corrigir os gases produzidos e a matéria orgânica fermentável residual, oriunda do inóculo. Nesse sentido, Araujo (2010) estudou o uso de "brancos" com aditivos ou "brancos" sem aditivos na estimativa de produção de gás líquido e $\mathrm{CH}_{4} \mathrm{e}$ verificou que $\mathrm{o}$ uso de "brancos", sem aditivos, superestimou o efeito dos aditivos testados. Tal fato o levou a sugerir o uso de "brancos" com aditivo quando forem realizados estudos com inclusão de modificadores ruminais.

Os objetivos da técnica de produção de gás devem ser examinados, se o objetivo é simular o animal, ou a fermentação in vitro do substrato ser considerada como uma característica por si só. Diante disso, torna-se importante realizar a padronização dos métodos já existentes, e aceitar que a fermentabilidade máxima de um substrato in vitro não pode imitar o que ocorre em animais, mas que é uma medida útil para auxiliar na formulação de ração e outras questões relacionadas à nutrição de ruminantes (RYMER et al., 2005).

A literatura dispõe de vários métodos para avaliação de alimentos para ruminantes, no entanto, a escolha do método adotado deve buscar maior precisão das estimativas. Dessa forma, os recursos disponíveis, financeiros e operacionais e, ainda, a possibilidade de implantação da técnica devem ser avaliados.

Pesquisas com animais em pastejo são mais complexas do que em animais confinados, o que exige maior discernimento na escolha das técnicas a serem utilizadas e determina o sucesso e credibilidade dos dados. O emprego de indicadores é uma alternativa bastante difundida pela grande variabilidade de opções e, a depender do indicador, facilidade de uso e baixo custo, possibilita a estimativa de consumo e digestibilidade nos diferentes compartimentos gastrintestinais.

Os métodos in vitro e in situ são de grande utilidade, devido à rapidez e ao baixo custo na avaliação do valor nutritivo dos alimentos, para auxiliar na formulação de ração e outras questões relacionadas à nutrição de ruminantes.

\section{REFERÊNCIAS}

ARAÚJO, R.C. Óleos essenciais de plantas brasileiras como manipuladores de fermentação ruminal in vitro. $2010.178 \mathrm{p}$. Tese (Doutorado em Ciências) - Escola Superior de Agricultura, Universidade de São Paulo, Piracicaba.

BELENGUER, A.; YAÑEZ, D.; BALCELLS, J.; OZDEMIR BABER, N.H.; GONZALEZ RONQUILLO, M. Urinary excretion of purine derivatives and prediction of rúmen microbial outflow in goats. Livestock Productions Science, v.77, p.127135, 2002.

BERCHIELLI, T.T.; VEGAGARCIA, A.; OLIVEIRA, S.G. Principais técnicas de avaliação aplicadas em estudo de nutrição. In: BERCHIELLI, T.T.; PIRES, A.V.; OLIVEIRA, S.G. (Eds). Nutrição de Ruminantes. 2.ed. Jaboticabal: Funep, 2011. p.565-600.

BLÜMMEL, M.; ØRSKOV, E.R. Comparison of gas production and nylon bag degradability of roughages in predicting feed intake in cattle.

\section{Animal Feed Science and}

Technology, v.40, p.109-119, 1993. 
CAMPOS, F.P. Métodos de análises de alimentos. In: CAMPOS, F.P.; NUSSIO, C.M.; NUSSIO, L.G. (Eds.). Piracicaba: FEALQ, 2004. 135p.

CASALI, A.O.; DETMANN, E.; VALADARES FILHO, S.C.; PEREIRA, J.C.; CUNHA, M.; DETMANN, K.S.C.; PAULINO, M.F. Estimação de teores de componentes fibrosos em alimentos para ruminantes em sacos de diferentes tecidos. Revista Brasileira de Zootecnia, v.38, n.1, p.130-138, 2009.

CASALI, A.O.; DETMANN, E.; VALADARES FILHO, S.C.; PEREIRA, J.C.; HENRIQUES, L.T.; FREITAS, S.G.; PAULINO, M.F. Influência do tempo de incubação e do tamanho de partículas sobre os teores de compostos indigestíveis em alimentos e fezes bovinas obtidos por procedimentos in situ. Revista Brasileira de Zootecnia, v.37, n.2, p.335-342, 2008.

CARVALHO, P.C.F.; KOZLOSKI, G.V.; RIBEIRO FILHO, H.M.N.; REFFATTI, M.V.; GENRO, T.C.M.; EUCLIDES, V.P.B. Avanços metodológicos na determinação do consumo de ruminantes em pastejo.

Revista Brasileira de Zootecnia, v.36, p.151-170, 2007. Supl. especial.

CHEN, X.B.; MEJIA, A.T.; ORSKOV, E.R. Evaluation of the use of the purine derivative: creatinine ratio in spot urine and plasma samples as an index of microbial protein supply in ruminants: studies in sheep. Journal of

Agricultural Science, v.125, p.137-143, 1995.

DESCHAMPS, F.C. Implicações do período de crescimento na composição química e digestão dos tecidos de cultivares de capim elefante. Revista

Brasileira de Zootecnia, v.28, p.11781189, 1999.
DECRUYENAERE, V; LECOMTE, P.; DEMARQUILLY, C.; AUFRÈRE, J.; DARDENNE, P.; STILMANT, D.; BULDGEN, A. Evaluation of green forage intake and digestibility in ruminants using near infrared reflectance spectroscopy (NIRS): Developing a global calibration.

Animal Feed Science and

Techonology, v.148, p.138-156, 2009.

DOVE, H.; MAYES, R.W. Plant wax components: a new approach to estimating intake and diet composition in herbivores. Journal of Nutrition, v.126, p.13-26, 1996.

DOVE, H.; MAYES, R.W. The use of plant wax alkanes as markers substances instudies of the nutrition of herbivores: a review. Australian Journal of Agricultural Research, v.42, p.913-957, 1991.

DOVE, H.; MAYES, R.W.; LAMB, C.S.; ELLIS, K.J. Factors influencing the release rate of alkanes from an intraruminal, controlled-release device, and the resultant accuracy of intake estimation in sheep. Australian Journal of Agricultural Research, v.53, p.681- 696, 2002.

ELWERT, C.; DOVE, H. Estimation of roughage intake in sheep using a known daily intake of a labelled supplement.

Journal of Animal Science, v.81, p.47$56,2005$.

FERREIRA, L.M.M.; OLIVÁN, M.; RODRIGUES, M.A.M.; GARCIA, U.; OSORO, K. Validation of the alkane technique to estimate diet selection of goats grazing heather-gorse vegetation communities. Journal of the Science of Food and Agriculture, v.85, p.6361646, 2005. 
FERREIRA, M.A.; VALADARES FILHO, S.C.; MARCONDES, M.I.; PAIXÃO, M.L.; PAULINO, M.F.; VALADARES, R.F.D. Avaliação de indicadores em estudos com ruminanteS: digestibilidade. Revista Brasileira de Zootecnia, v.38, n.8, p.1568-1573, 2009.

FONTANELI, R.S.; CHEFFERBASSO, S.M.; DÜRR, J.W.; APPELT, J.V.; BORTOLINI, F.; HAUBERT, F.A. Predição da composição química de bermudas (Cynodon spp.) pela espectroscopia de reflectância no infravermelho proximal. Revista Brasileira de Zootecnia, v.33, p.838842, 2004.

FUJIHARA, T.; ØRSKOV, E.R.; REEDS, P.J.; KYLE, D.J. The effect of protein infusion on urinary excretion of purine derivatives in ruminants nourished by intragastric nutrition.

Journal of Agricultural Science, v.109, p.7-12. 1987.

FUKUMOTO, N.M.; DAMASCENO, J.C.; ROEHSIG, L.; CÔRTES, C.; MATSUSHITA, M.; dos SANTOS, G.T. Estimativas da digestibilidade e consumo de matéria seca em ovinos alimentados com feno de aveia e concentrado em resposta ao método de administração de alcano externo C32. Revista Brasileira de Zootecnia, v.35, p.2413-2420, 2006.

GETACHEW, G.; DEPETERS, E.J.; ROBINSON, P.H.; FADEL, J.G. Use of an in vitro rumen gas production technique to evaluate microbial fermentation of ruminant feeds and its impact on fermentation products. Animal Feed Science and Technology, v.123, p.547-559, 2005.
GONZÁLES-RONQUILLO, M.;

BALCELLS J.; BELENGUER, A.; CASTRILLO, C.; MOTA, M. A

Comparison of Purine Derivatives

Excretion with Conventional Methods as Indices of Microbial Yield in Dairy Cows. Journal of Dairy Science, v.87, p.2211-2221, 2004.

HENDRICKSEN, R.E.; REICH, M.M.; ROBERTON, R.F.; REID, D.J.; GAZZOLA, C.; RIDEOUT, J.A.; HILL, R.A. Estimating the voluntary intake and digestibility of buffelgrass and lucerne hays offered to Brahman-cross cattle using n-alkanes. Animal Science, v.74, p.567-577, 2002.

KELI, A.; ANDUEZA,D.; DEVEGA, A.; GUADA, J.A. Validationof the n-alkane and NIRS techniques to estimate intake, digestibility and diet composition in sheep fed mixed lucerne:ryegrass diets. Livestock Science, v.119, p.42-54, 2008.

KOZLOSKI, G.V.; FIORENTINI, G.; HÄRTER, C.J.; SANCHEZ, L.M.B.C. Uso da creatinina como indicador da excreção urinária em ovinos. Ciência Rural, v.35, p.98-102, 2005.

LANA, R.P. Nutrição e alimentação animal: mitos e realidades. 2 .ed. Viçosa: Universidade Federal de Viçosa, 2007.344p.

LEWIS, R.M.; MAGADLELA, A.M.; JESSOP, N.S.; EMMANS, G.C. The ability of the n-alkane technique to estimate intake and diet choice of sheep. Animal Science, v.77, p.319-327, 2003.

MAKKAR, H.P.S.; BLÜMMEL, M.; BECKER, $K$. In vitro effects and interactions between tannins and saponins and fate of tannins in the rumen. Journal of the Science of Food and Agriculture, v.69, n.4, p.481-493, 1995. 
MEHREZ, A.Z.; ØRSKOV, E.R. A study of the artificial fiber bag technique for determining the digestibility of feeds in the rumen. Journal of Agricultural Science, v.88, p.645, 1977.

MENKE, B.K.H.; RAAB, L.; SALEWSKI, A. The estimation of the digestibility and metabolizable energy content of ruminant feedingstuffs from the gas production when they are incubated with rumen liquor in vitro.

Journal of Agricultural Science, v.93, p.217-223, 1979.

MOLINA, D.O.; MATAMOROS, I.; PELL, A.N. Accuracy of estimates of herbage intake of lactating cows using alkanes: comparison of two types of capsules. Animal Feed Science and Technology, v.114, p.241-260, 2004.

MORAIS, J.A.S.; BERCHIELLI, T.T.; VEGA, A.; QUEIROZ, M.F.S.; KELI, A.; REIS, R.A.; BERTIPAGLIA, L.M.A.; SOUZA, S.F. The validity of $n$-alkanes to estimate intake and digestibility in Nellore beef cattle fed a tropical grass (Brachiaria brizantha cv. Marandu). Livestock Science, v.135, p.184-192, 2011.

NOCEK, J.E. In situ and other methods to estimate protein and energy digestibility. A review. Journal of Dairy Science, v.71, p.2051, 1988.

OLIVÁN, M.; FERREIRA, L.M.M.; CELAYA, R.; OSORO, K. Accuracy of the n-alkane technique for intake estimates in beef cattle using different sampling procedures and feeding levels. Livestock Science, v.106, p.28-40, 2007.
OLIVEIRA, A.P.; SALIBA, E.O.S.; BORGES, I..; AROEIRA, L.J.M.; GONTIJO NETO, M.M.; AMARAL, T.B., Concentração de Óxido Crômico e LIPE® nas fezes de bovinos em pastagens de Brachiaria brizantha utilizadas nas estimativas de consumo In: REUNIÃO DA SOCIEDADE BRASILEIRA DE ZOOTECNIA, 42, 2005, Goiânia. Anais... Goiânia: Sociedade Brasileira de Zootecnia, 2005.

ØRSKOV, E.R.; REID, G.W.; KAY, $M$. Predicting of intake by cattle from degradation characteristics of roughage. Animal Production, v.46, p.29, 1988.

PELL, A.N.; SCHOFIELD, P. Computerized monitoring of gas production to measure forage digestion in vitro. Journal of Dairy Science, v.76, p.1063-1073, 1993.

RENNÓ, L.N.; VALADARES, R.F.D.; LEÃO, M.I.; VALADARES FILHO, S.C.; SILVA, J.F.C.; CECON, P.R.; DIAS, H.L.C.; COSTA, M.A.C.; OLIVEIRA, R.V. Estimativa da produção de proteína microbiana pelos derivados de purinas na urina em novilhos. Revista Brasileira de Zootecnia, v.29, p.1223- 1234, 2000.

RYMER, C.; HUNTINGTON, J.A.; WILLIAMS, B.A.; GIVENS, D.I. In vitro cumulative gas production techniques: History, methodological considerations and challenges. Animal Feed Science and Technology, v.123, p.9-30, 2005.

SADER, A.P.O.; OLIVEIRA, S.G.; BERCHIELLI, T.T. Application of kjeldahl and dumas combustion methods for nitrogen analysis. Archives of Veterinary Science, v.9, p.73-79, 2004. 
SALIBA, E.O.S.; RODRIGEZ, N.M.; PILÓ-VELOSO, D.; TEIXEIRA, D.P.; PEREIRA, S.L. Estudo comparativo da coleta total com a lignina purificada como indicador de digestibilidade para ovinos em experimento com feno de Tifton 85. In: REUNIÃO ANUAL DA SOCIEDADE BRASILEIRA DE ZOOTECNIA, 40., 2003, Santa Maria. Anais... Santa Maria: Sociedade Brasileira de Zootecnia, 2003a.

SALIBA, E.O.S.; RODRIGEZ, N.M.; PILÓ-VELOSO, D. Utilization of purified lignin extracted from Eucalypitus grandis (PELI), used as na external marker in digestibility trials in various animal species. In: WORLD CONFERENCE ON ANIMAL PRODUCTION, 9, 2003, Porto Alegre. Proceedings... Porto Alegre, RS, 2003b.

SALIBA, E.O.S. Uso de indicadores: passado, presente e futuro. In: TELECONFERÊNCIA SOBRE INDICADORES EM NUTRIÇÃO ANIMAL, 1., 2005, Belo Horizonte. Anais... Belo Horizonte: Universidade Federal de Minas Gerais, 2005. p.4-22.

SANTOS, R.A.; TEIXEIRA, J.C.; PÉREZ, J.R.O.; PAIVA, P.C.A.; MUNIZ, J.A.; ARCURI, P.B. Estimativa da degradabilidade ruminal de alimentos utilizando a técnica de produção de gás em bovinos, ovinos e caprinos. Ciência e Agrotecnologia, v.27, p.689-695, 2003.

SENGER, C.C.D.; KOZLOSKI, G.V.; SANCHEZ, L.M.B.; MESQUITA, F.R.; ALVES, T.P.; CASTAGNINO, D.S. Evaluation of autoclave procedures for fiber analysis in forage and concentrate feedstuffs. Animal Feed Science and Technology, v.146, p.169-174, 2008.
SILVA, D.J.; QUEIROZ, A.C. Análise de alimentos: métodos químicos e biológicos. 3.ed. Viçosa: Editora UFV, 2002. 235p.

THEODOROU, M.K.; WILLIAMS, B.A.; DHANOA, M.S.; MCALLAN, A.B.; FRANCE, J. A simple gas production method using a pressure transducer to determine the fermentation kinetics of ruminant feeds. Animal Feed Science and Technology, v.48, n.1, p.185-197, 1994.

TILLEY, J.M.A.; TERRY, R.A. A two stages technique for the in vitro digestion of forage crops. Journal of British Grassland Society, v.18, p.104, 1963.

TITGEMEYER, E.C.; ARMENDARIZ, C.K.; BINDEL, D.J.; GREENWOOD, R.H.; LOEST, C.A. Evaluation of titanium dioxide as a digestibility marker for cattle. Journal of Animal Science, v.79, n.4, p.1059-1063, 2001.

VAN HELLEN, R.W.; ELLIS, W.C. Samples container porosities for rumen in situ studies. Journal of Animal Science, v.44, p.141-146, 1977.

VALADARES FILHO, S.C.; PINA, D.S. Fermentação Ruminal. In: BERCHIELLI, T.T.; PIRES, A.V.; OLIVEIRA, S.G. (Eds). Nutrição de Ruminantes. 2006. p.151-182.

VALADARES FILHO, S.C.; MORAES, E.H.B.K.; DETMANN, E.; PAULINO, M.F.; VALADARES, R.F..D.; MORAES, K.A.K.; MARCONDES, M.I Perspectiva do uso de indicadores para estimar o consumo individual de bovinos alimentados em grupo. In: REUNIÃO ANUAL DA SOCIEDADE BRASILEIRA DE ZOOTECNIA, 43., 2006. João Pessoa. Anais... João Pessoa: Sociedade Brasileira de Zootecnia, 2006. p.291-322. 
VALIENTE, O.L.; DELGADO, P.;

VEGA, A.; GUADA, J.A. Validation of the nalkane technique to estimate intake, digestibility, and diet composition in sheep consuming mixed grain:roughage diets. Australian Journal of Agricultural Research, v.54, p.693-702, 2003.

VANZANT, E.S.; COCHRAN, R.C.; TITGEMEYER, E.C. Standardization of in situ techniques for ruminant feedstuff evaluation. Journal of Animal Science, v.76, p.2717, 1998.
YU, P.; EGAN, A.R.; BOON-EK, L. LEURY, B.J. Purine derivative excretion and ruminal microbial yield in growing lambs fed raw and dry roasted legume seeds as protein supplements. Animal Feed Science and Technology, v.95, p.33-48, 2002.

Data de recebimento: 10/11/2011

Data de aprovação: 14/11/2012 